\title{
TRIZ ile Yenilikçi Mühendislik Eğitimini Tasarlama
}

\author{
Metin Orhan Kaya \\ İstanbul Teknik Üniversitesi, Uçak ve Uzay Bilimleri Fakültesi, Uçak Mühendisliği Bölümü, ORCID: 0000-0003-1589-8100
}

\begin{abstract}
Özet
Ülkemizde inovasyon kelimesi çok sık kullanılmakla beraber, temel taşlarından biri olan fikir üretme konusunda yeterince farkındalık oluşmadığı gözlemlenmiștir. Bu yazıda çok sayıda fikir üretme tekniği arasından yıldızı gittikçe daha çok parlayan TRIZ konusunda temel bilgilendirme yapılacak ve TRIZ'in dünyanın değişik üniversitelerinde mühendislik öğrencilerine nasıl verildiği ve başarı durumları tartışılacaktır.
\end{abstract}

Anahtar Kelimeler: TRIZ, Mühendislik Eğitimi, Eğitim Tasarımı

\begin{abstract}
In our country, it is observed that innovation word is used very frequently, but there is not enough awareness about producing ideas. In this article, we will provide basic information about TRIZ, which is increasingly shining among the many ideas generation tools and discuss how TRIZ is given to engineering students in different universities of the world and their success status.
\end{abstract}

Keywords: TRIZ; Engineering Education, Education Design

\section{Gíriş}

Değişimin çok hızlı olduğu bu dönemde inovasyonun önemi gittikçe artmıştır. Yeni buluşlar yeni teknolojilere yol açmaktadır. Yeni teknolojiler yeni endüstrilere öncülük etmektedir. Son olarak yeni endüstriler de yeni iş yetenekleri gereksinimlerine yol açmaktadır. İş yerleri bilgi tabanlılıktan yetenek tabanlılığa doğru kaymıştır. Bu kayma iş yerlerinde son zamanlarda istenen yeteneklerden de gözlemlenebilmektedir (Issac Lim Sing Sheng, Khoo Boon How, Tan Eng Hoo, 2015).

Özel bilgi birikimi, uygun iş tecrübesi zamanında çok önemsenirken günümüzde önemini yitirmiştir. Son zamanlarda daha çok yaratıcı problem çözme, stratejik düşünme ve analitik düşünme konuları önem kazanmaya başlamıştır. Son söylenen yeteneklerin inovasyon ile ilintili yetenekler olduğuna dikkat edilmelidir. Genel düşünme yetenekleri, belirli bir konuda bilgi birikim ya da iş tecrübesinden daha fazla tercih edilmektedir.

Karşımıza çıkan problemleri en basit olarak çözümü bilinen veya bilinmeyen olarak ikiye ayırabiliriz. Çözümü bilinen veya iyi yapılandırılmış problemler genelde okulda karşımıza basitleştirilmiş olarak gelen problemlerdir. Genelde çözümleri kitap, makale veya konunun uzmanla-

*Yazışma Adresi / Address for Correspondence:

Metin Orhan Kaya, Email: kayam@itu.edu.tr

Geliş Tarihi / Received Date: 04.09.2018

Kabul Tarihi / Accepted Date: 24.07.2018

Doi: $10.26701 /$ uad. 413706 rından bulabiliriz. Çözümü bilinmeyen problemler yaratıcı problem olarak adlandırılır. Bu tip problemlerin çoğu zaman tek bir cevabı olmayacaktır. Yaratıcı problemlerin de çok basit ve zorlarının olacağını kolaylıkla söyleyebiliriz. Genelde yaratıcı problemlerin \% 77'si kişisel ve yakın çevre/şirket birikimiyle çözülebilmektedir. Günümüzün yarışmacı dünyasında bu çözümlerin fark oluşturmayacağı kolaylıkla söylenebilir. Fark yaratan çarpan etkisi büyük çözümler için özel düşünme eğitiminden geçilmesi gerekir. Yüzlerce fikir üretme tekniği (Beyin Fırtınası, Scamper, Sinektik, Yanal Düşünme vb ) psikolojik ataleti kırmaya odaklanmıștır, rastgeledir ve kişinin basitleștirme yeteneğine bağlıdırlar.

\section{TRIZ}

TRIZ 1950'lerden itibaren Rusya'da kullaniliyor olmasına rağmen batı dünyasına girişi 1990'nın başlarında olabilmiştir. TRIZ konusunda çok sayıda kitap yazılmıştır (Karen Gadd, 2011;Leonid Chechurin, 2016; Michael A. Orloff, 2017; H. James Harrington, 2017).

Triz içinde çok sayıda teknikleri barındıran sistematik fikir üretme topluluğudur. Triz 1926'da Sovyetler Birliği Taşkent'de doğan Genrich Altshuller tarafından ortaya konulmuştur. Teoriya Resheniya Izobretatelskikh Zadatch (Теория Решения Изобретательских ЗаАач) kelimelerinin baş harflerinden ortaya çımıştır. Altshuller 1946'da patent subayı olarak atandıktan sonra çok sayıda patent incelemiş ve bu patentlerin arkasındaki temel fikirleri yakalayarak TRIZ'in ortaya çıkmasını sağlamıștır. 
TRIZ size problemin çözümünün yaklaşık olarak neye benzediğini söyler. Örneğin $1 \mathrm{~km}$ karelik bir alanda hazine olsun. Önceden nerede olduğunu bilmediğimiz için her yeri tek tek kazmamız gerekir. Bizden önce başkaları da kazmış ise şanslı sayılırız en azından oraları kazmamıza gerek kalmaz. TRIZ ise sizi boş yere tüm alanı kazmanıza gerek bırakmadan örneğin 10 metre karelik bir alanda kazı yaparak hazineyi bulmanızı sağlar. Doğrudan hazineyi buldurmaz, eninde sonunda deneme/yanılma veya beyin firtınası gibi tekniklere ihtiyacınız olacaktır. Yani bir program yapalım düğmeye bastığımızda bize doğrudan buluş yapsın diye bir beklenti içinde olmamamız gerekir. Program sizi çözüme oldukça yaklaştıracaktır.

Klasik TRIZ (Yaratıcı Problem Çözme Teorisi) çok sayıda problem çözme ve teknoloji ön kestirim araçlarını içinde barındırır. Bu araçlar: 40 Buluş Prensibi, 39x30 Çelişki Matrisi, İdeallik, 9 Pencere Yaklaşımı, Teknik Sistemlerin Gelişimi, Kaynak Kullanımı, Fonksiyonel Analiz, Cisim-Alan Prensibi, 76 Buluş Standartı, Minik Cüceler Topluluğu, Bilimsel Etkiler, Boyut, Zaman, Maliyet Operatörleri ve ARIZ.

Altshuller tüm bu teknikleri bir çırpıda geliştirmemiştir. Aşağıda bazı tekniklerin geliştirilme tarihlerini görebilirsiniz.

\section{Prensip}

1946-1971

ARIZ-Algorithm of Inventive Problem Solving 1959-1985

Ayrılık Prensipleri

1973-1985

Madde-Alan (Su Field) Analizi

1973-1985

Standart Çözümler

1975-1985

Doğal Etkiler (Bilimsel Etkiler)

1970-1980

Teknik Sistemlerin Evrim Kalıpları

$1975-1980$

TRIZ eğitiminin ne kadar sürede verileceği konusunda bir anlaşma bulunmamaktadır. Ruslar 500 saatlik bir eğitimi öngörürken Samsung firması işe her giren elemanına 80 saatlik temel Triz eğitimi vermektedir. Batıda mühendislere yönelik olarak 2 günlük eğitimden 2 haftalık eğitime kadar farklı uygulamalar bulunmaktadır.

TRIZ çatısı altında bulunan tekniklerden bir kısmı hakkında bilgi verilecektir.

\section{Çelişki Teknikleri}

Çelişkileri iki gruba ayırmak mümkündür. Birinci grupta bir özellik iyileşirken başka bir özellik kötüleşir. Örnek: Penisilin mikropları öldürürken yararlı dokulara da zarar verir. Bu tip çelişkiye teknik çelişki adı verilir. Diğer gurup çelişkide ise birbiriyle çelişen iki özelliğin aynı anda olması durumu vardır. Örnek: "Kahve güzel içimli olması için sıcak, müsterinin yanmaması için de soğuk olmalıdır” Bu tip çelişkiye ise fiziksel çelişki adı verilir.

Fiziksel çelişkileri çözmek için ayırma prensipleri kullanılırken teknik çelişkileri çözmek için 39x39 çelişki matrisi kullanılır.
Ayrılık Prensipleri

- Zamanda ayrilık

- Uzayda ayrılık

- Sistemin bütünü ve parçaları arasındaki ayrılık

- Koşula göre ayrılık

\section{Su-Field Analizi}

Altschuller 1970'in ortalarında yeni bir problem çözüm tekniği olan Madde-Alan (Substance-Field) veya kısaca SuField analizi ve bununla beraber kullanilan 76 standart çözümü ortaya atmıştır. Bu teknik, problemi çözmek için çelişkileri ortaya koyup daha sonra da çözme yoluna gitmez. Bunun yerine sistemdeki eksikleri, zararları arama ve çözüm önerme, sistemde bazı parametrelerin ölçülmesi, aranması ve son olarak da sistemin evriminin bulunmasını amaçlar.

Bir problemi madde-alan tekniğiyle çözebilmek için öncelikle problemin grafiksel gösterimi elde edilir. Bu gösterimde iki madde ve bunlar arasında etkileşim (field) çizilir. Başka kaynaklarda farklı tariflere rastlayabilirsiniz (örneğin: object-tool-energy triangle), ama sonuçta hepsi aynı yere varacaktır. Madde (substance), Alan (field) denilince aşağıda görüldüğü gibi her şey olabilir.

Su (Subject-Cisim) : Çivi,Klavye,Gemi...

Field (Alan): Mekanik, Kimyasal, Termal, Manyetik...

Ideallik

Öyle bir sistem düşünün ki hiçbir enerji harcamıyor, maliyeti neredeyse sıfır, bakım gereksinmesi yok yan etkileri hiç yok. Böyle bir sistem tasarlanabilir mi veya mevcut bir sistem bu hale getirilebilir mi? Cevap basit: Tam olarak yapamasak da yaklaşabiliriz ki tasarımcı olarak hedefimiz bu olmalı.

Ideale ne kadar yaklaşırsak o kadar inovatif çözüm üretmiş oluruz ki bu da bizi dünyayla yarışma noktasına getirir. Ideal çözüm üretirken kaynak (resource) kullanımı da her zaman beraber düşünülür. Makine mühendisliği vb konularda inovasyon konuşuyorsak malzeme konusundaki yeniliklerden sürekli haberdar olmak zorundayı. $\mathrm{Bu}$ malzemeleri kullanmak için malzeme mühendisi olmaya gerek yok. Benzer mantık işletme inovasyonlarına da kolaylıkla adapte edilebilir.

Kaynak (Resource) Kullanımı

Sisteme uygun kaynak (Resource) bulmak Triz tekniklerinden biridir. Bazı kaynaklar çok kolay, bazılarıyla çok zor bulunabilir.

Kaynaklar, cisim (substance) veya field (alan) olarak bulunabilirler.

Sistem İçi Kaynaklar: Çelişkinin olduğu sistemin içindeki kaynaklar

Çevresel Kaynaklar: Çelişkinin olduğu sistemin çevresin- 
de bulunan kaynaklar. Dünyanın manyetik ve çekim kuvveti, Güneş vb..

Tüm Sistem Kaynakları: Başka sistem tarafından atık olarak üretilen (yan ürün) veya başka cisimler tarafından üretilen ucuz veya maliyetsiz kaynaklar

TRIZ'in Mühendislik Öğrencilerinin Eğitiminde Kullanılması

Sadettin Kapucu, Nihat Ylldırım (2007), tarafindan yapılan araştırmada Gaziantep Üniversitesi Makine Mühendisliği 4. sınıftan 16 öğrenciye 2006-2007 tarihleri arasında "Mühendislik Tasarımlarında Yaratıcı Sorun Çözme" dersi verilmiş. Öğrenciler dörderli gruplara ayrılmış ve her birine farklı proje verilmiştir. Verilen projeler:

1) Tekstil sektörüne yönelik olarak İp tansiyonlama germe aparatı

2) Gıda sektörüne yönelik, yuvarlama makinesi

3) Gıda sektörüne yönelik zeytin hamuru yapma makinesi

4) Tekstil sektörüne yönelik atkı atma mekanizması

Dersi alan tüm öğrencilere dersin öğrenciler üzerindeki etkilerini anlamaya yönelik Likert tipi bir anket yaptırılmıştır. Anket sonucunda öğrencilerin bu eğitimden çok yararlandıkları ortaya çıkmıştır.

Iouri Belski,James Baglin ve Jennifer Harlim (2013), Avustralya'da Royal Melbourne Teknoloji Enstitüsü'nde 93 öğrenci üzerinde yapılan çalışmada Wilcoxon ranksum testi uygulamışlar ve TRIZ öğretilen öğrencilerin problem çözme yeteneklerinin çok arttığını gözlemlemişler. Öğrencilere TRIZ'in bir çok tekniği öğretilmiş.

Issac Lim Sing Sheng, Khoo Boon How, Tan Eng Hoo (2015), Malezya Monash Üniversitesin de 91 tane lisans birinci sınıf öğrencisine iki ay boyunca pilot program uygulamışlar. Öğrenciler mühendislik, bilgi teknolojileri, işletme gibi farklı branşlardan oluşmuş. Sadece \%10'u mühendislik öğrencisi. Öğrenciler guruplar halinde (15 grup) çalışmış ve her birine Myers Briggs kişilik testi uygulanmış. Öğrencilere maliyeti 30 \$ ile sınırlı olacak projeler verilmiş ve karşlaştıkları problemleri TRIZ ile çözmeleri istenmiş. Farklı zorluk seviyesinde olan projelerin bazılarını öğrenciler kendileri seçmişler, bazıları da öğretmen tarafından verilmiş. Vidasız geçmeli kap, sofra takımı strelize eden araç, otomatik kapanan kapı vb. gibi basit projerin yanısıra, mikro yanmalı motor, radyo güçlendirici cihaz, titreşim test donanımı vb zor projeler de yapılmış. Her bir takım, projelerini sözlü olarak anlatmışlar ve sonra da poster olarak sergilemişler. Sanayiden kişiler davet edilerek tasarımların teknolojik ve ekonomik yapılabilirliklerine göre değerlendirmeleri istenmiș.

Proje sonunda öğrencilerin TRIZ'den oldukça faydalandıkları ve bilgi seviyelerini ileri götürmek istedikleri gözlemlenmiş.
Yu-Shan Chang ve arkadaşları (2016), 121 tane birinci s1nıf öğrencisine TRIZ öğretip proje yaptırmışlar. Çok değişkenli kovaryans analizi kullanarak TRIZ'in öğrencilerin problemleri analiz etmelerinde ve strateji geliştirmelerine çok pozitif katkısı olduğunu bulmuşlar. Öğrencilere 6 haftalık «Model Güneş Araçlarının Tasarlanması ve Yapılması» başlı̆ı altında TRIZ tabanlı bir eğitim verilmiş. Öğrencilerden sınırlı kaynak kullanarak (iki güneș paneli ve bir motor) engelleri aşabilecek bir güneş arabası tasarlamaları istenmiş. Gerekli birleştirme teknikleri ve dişli (Şekil 1) spesifikasyonu kullanarak aştıkları engel (Şekil 2) kadar puan almaları sağlanmış.
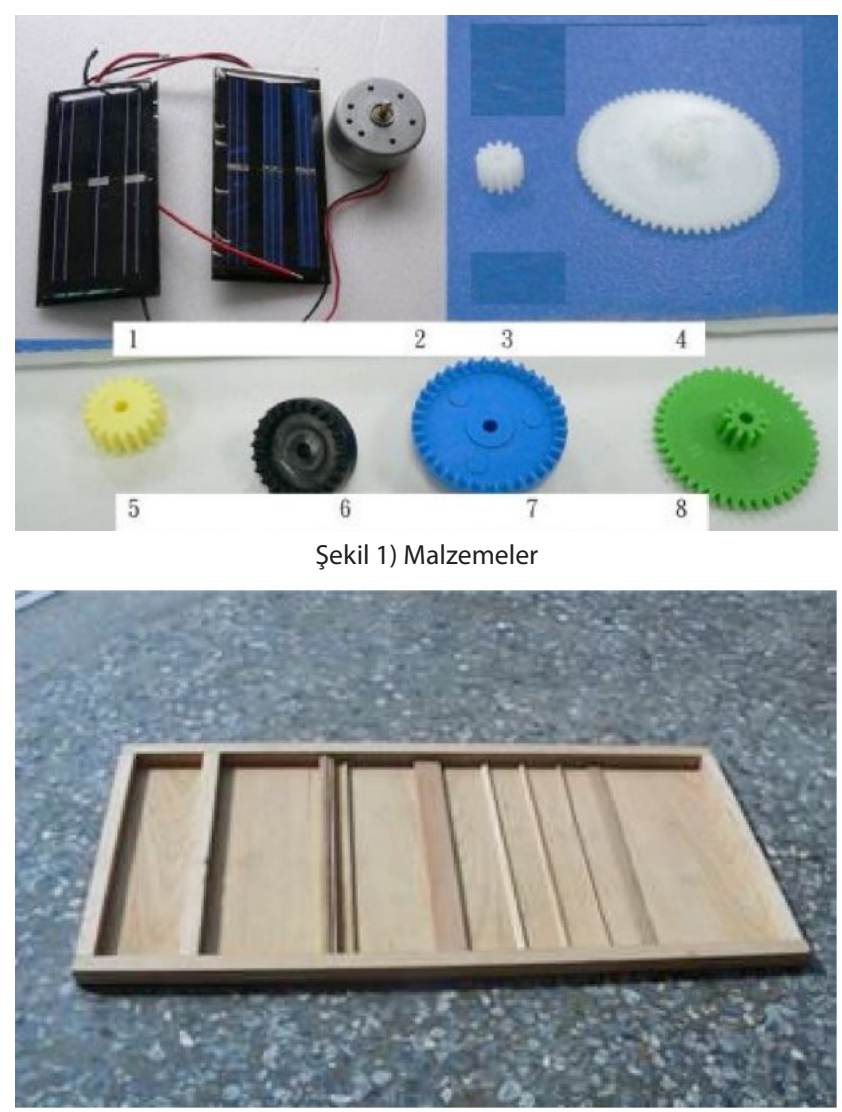

Şekil 2) Engel

Iouri Belski, Pavel Livotov, Oliver Mayer (2016), Almanya'daki Offenburg Üniversitesi Uygulamalı Bilimlerden 90 öğrenciyle deney yapmışlar. Öğrenciler farklı sınıflardan seçilmiș. 3 gruba ayrılmışlar ve hepsine aynı problem verilmiş. Su borusu içindeki kirecin nasıl giderileceğine dair soru sorulmuș. 16 dakika zaman verilmiș. Öğrencilerin bir kısmı "random kelime" tekniği kullanırken diğer kısmı da TRIZ'in Su_Field tekniği kullanmış. Su-Field tekniğini kullananların açıkça daha iyi çözüm ürettikleri gözlemlenmiş.

Denis Dumasa, Linda C. Schmidt, Patricia A. Alexandera (2016), mid-Atlantic Amerikan Üniversitesindeki 44 yüksek lisans öğrencisiyle bir çalışma yapmışlar. Öğrencilerin yaşları 22-33 arasında değişiyormuş. Öğrencilerin üç farklı bilişsel yetenekleri incelenmiş: aykırı düşünme, işleyen bellek ve ilişkisel muhakeme. Öğrencilere yaratıcı tasarım görevi verilmiş. Nasıl yaklaştıkları TRIZ öğrenmeden önce ve sonra incelenmiş. t-eşleștirilmiş ör- 
nek testi uygulanmıș ve TRIZ'in orjinal tasarım yapmada çok faydası olduğunu bulmuşlar.

\section{SONUÇ}

Günümüzün yarışçı ortamı, mevcut bilgisini iyi kullanabilen mühendisten ziyade yaratıcı hatta henüz mevcut olamayan bilgiyi üretebilen mühendis gereksinmesini ortaya çıkarmaktadır. Bu ise eğitim sistemimizin kökten değişmesine gereksinim doğurmaktadır. Öğrencinin dersini önceden çalışıp sınıfta tartışma ortamı ile bilgisini pekiştirmesinden çok daha derin bir değişime gerek vardır. Bu değişim için eğiticilerimizin de değişmesi gerekliliği çok açıktır. Yaratıcı fikir üretme tekniklerinden TRIZ bu yazıda tartışılmıştır. Tek başına TRIZ'in yeterli olmayacağı açıktır.

Mühendislik öğrencilerine birinci sinıftan itibaren kademeli TRIZ eğitiminin verilmesinin özgün proje yapabilme yeteneklerini arttırdığı gözlenmiştir. TRIZ eğitimi verilirken mümkün olduğunca bir alet geliştirilmesi de teşvik edilmelidir. Böylece öğrenciler kendilerine verilen görevi yaparken problemle karşılaştıkça çözüm için TRIZ'i kullanacaklar ve daha özgün tasarımlar yapmaları mümkün olacaktır.

\section{KAYNAKLAR}

louri Belski,James Baglin ve Jennifer Harlim, Teaching TRIZ at University: a Longitudinal Study. International Journal of Engineering Education 2013, 29:346-354.
Denis Dumasa, Linda C. Schmidt, Patricia A. Alexandera, Predicting creative problem solving in engineering design, Thinking Skills and Creativity 21 (2016) 50-66

H. James Harrington (2017), Lean TRIZ How to Dramatically Reduce Product-Development Costs with This Innovative Problem-Solving Tool, CRC Press

louri Belski, Pavel Livotov, Oliver Mayer, Eight Fields of MATCEMIB Help Students to Generate More Ideas, Procedia CIRP 39 ( 2016 ) $85-90$

Issac Lim Sing Sheng, Khoo Boon How, Tan Eng Hoo, Teaching, Learning \& Applying TRIZ in University, THE 11th INTERNATIONAL MATRIZ CONFERENCE TRIZfest-2015, 10-12 Eylül 2015.

Karen Gadd (2011), Triz for Engineers, Enabling Inventive Problem Solving, A John Wiley \& Sons, Ltd., Publication

Leonid Chechurin (2016), Research and Practice on the Theory of Inventive Problem Solving (TRIZ) Linking Creativity, Engineering and Innovation, Springer, Finland

Michael A. Orloff (2017), ABC-TRIZ Introduction to Creative Design Thinking with Modern TRIZ Modeling, Springer

Sadettin Kapucu, Nihat Yıldırım, Mühendislik Öğrencilerine TRIZ ile Yenilikçi Problem Çözme Tekniklerinin Öğretilmesi, Mühendis ve Makina, 2007, Cilt : 48, Sayı 572

Yu-Shan Chang, Yu-Hung Chien, Kuang-Chao Yu, Yih-Hsien Chu, MavisYi-ching Chen, Effect of TRIZ on the creativity of engineering students, Thinking Skills and Creativity 19 (2016) 112-122 